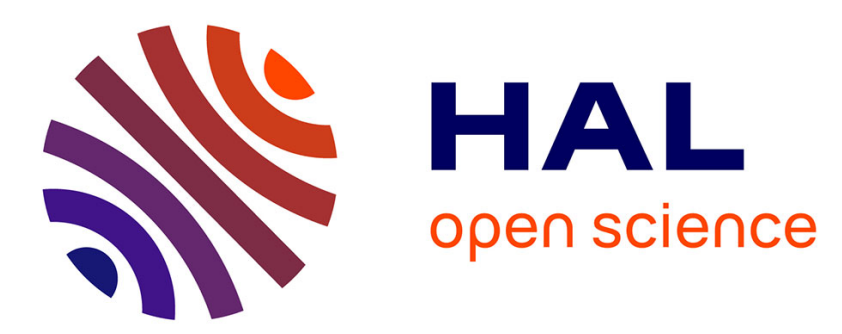

\title{
A Mindfulness-Based Intervention: Differential Effects on Affective and Processual Evolution
}

Pascal Antoine, Eva Andreotti, Anne Congard, Bruno Dauvier, Johan Illy, Rollon Poinsot

\section{- To cite this version:}

Pascal Antoine, Eva Andreotti, Anne Congard, Bruno Dauvier, Johan Illy, et al.. A MindfulnessBased Intervention: Differential Effects on Affective and Processual Evolution. Applied Psychology: Health and Well-Being, 2018, 10 (3), pp.368-390. 10.1111/aphw.12137 . hal-02186199

\section{HAL Id: hal-02186199 \\ https://hal.univ-lille.fr/hal-02186199}

Submitted on 19 Sep 2019

HAL is a multi-disciplinary open access archive for the deposit and dissemination of scientific research documents, whether they are published or not. The documents may come from teaching and research institutions in France or abroad, or from public or private research centers.
L'archive ouverte pluridisciplinaire HAL, est destinée au dépôt et à la diffusion de documents scientifiques de niveau recherche, publiés ou non, émanant des établissements d'enseignement et de recherche français ou étrangers, des laboratoires publics ou privés. 


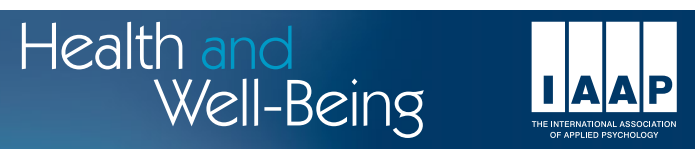

APPLIED PSYCHOLOGY: HEALTH AND WELL-BEING, 2018

doi:10.1111/aphw.12137

\title{
A Mindfulness-Based Intervention: Differential Effects on Affective and Processual Evolution
}

\author{
Pascal Antoine* and Eva Andreotti \\ University of Lille, France \\ Anne Congard and Bruno Dauvier \\ Aix-Marseille University, France \\ Johan Illy and Rollon Poinsot \\ Immanence SAS, Manosque, France
}

\begin{abstract}
Objectives: A 20-minutes-a-day, self-help, mindfulness-based intervention was conducted for 6 weeks with a French community sample. First, the intervention effects on affective and functioning variables were evaluated. Then, a differential approach was used to examine improvement potentiality and the perceived benefits of mindfulness according to the participants' baseline mindfulness competencies. Method: Participants were non-randomly assigned to a control group on the waiting list $(n=44)$ or a mindfulness group $(n=47)$. Self-report measures assessed anxiety, depression, psychological distress, mindfulness, negative self-oriented cognition, and experiential avoidance. Results: Improvements in the variables were observed for the mindfulness group but not for the control group, with effect sizes ranging between .53 and .88 . Low baseline levels of mindfulness predicted greater improvement in mindfulness $(r=-0.55, p<.001)$ than high baseline levels. Conclusions: Mindfulness practice elicited several positive outcomes regarding affective variables, highlighting emotional functioning changes.
\end{abstract}

Keywords: affect, differential approach, emotional functioning, mindfulness, self-help intervention

\section{INTRODUCTION}

Growing evidence supports the somatic and psychological health improvements induced by mindfulness-based interventions (Cavanagh et al., 2013). An investigation of the impact of mindfulness has revealed promising public health

* Address for correspondence: Pascal Antoine, Laboratoire SCALab UMR CNRS 9193, Université Lille 3 BP 60149, 59653 Villeneuve d'Ascq Cedex, France. Email: pascal.antoine@univ-lille3.fr 
implications, such as positive emotional functioning and enhanced mental health (Hazlett-Stevens \& Oren, 2017).

Definitions of mindfulness often encompass present-oriented attentional components in addition to a curious and non-judgmental attitudinal stance towards the full experience of the here-and-now, including inner physical sensations, emotions, cognitions, and environmental stimuli (Greco, Baer, \& Smith, 2011; Kabat-Zinn, 1996). The "mental training" of mindfulness cultivates a shift in focus towards non-reactivity, decentered perspective and acceptance, thereby helping individuals reduce their stress vulnerability, automatism, and emotional distress (Bishop et al., 2004). Mindfulness-based interventions aim at expanding individual self-regulation competencies, including emotion and attention regulation (Carmody \& Baer, 2009; Hazlett-Stevens \& Oren, 2017). Therefore, these interventions do not intend to change what an individual experiences; rather, they suggest a different way of experiencing based on non-judgmental awareness and acceptance (Cavanagh et al., 2013).

Mindfulness-Based Stress Reduction (MBSR; Kabat-Zinn, 1990), initially created in a medical setting, and Mindfulness-Based Cognitive Therapy (MBCT; Segal, Williams, \& Teasdale, 2002), which focuses on the prevention of depression relapse, are long-established, intensive, 8-week, mindfulness-based group interventions. These interventions result in favorable outcomes in terms of subthreshold variables and disorders-for example, anxiety, depression, and perceived stress (Baer, Carmody, \& Hunsinger, 2012; Chiesa \& Serretti, 2009; Goyal et al., 2014; Hofmann, Sawyer, Witt, \& Oh, 2010; Khoury, Sharma, Rush, \& Fournier, 2015; Nyklíček \& Kuijpers, 2008; Strauss, Cavanagh, Oliver, \& Pettman, 2014) - and are effective in promoting subjective and psychological well-being, quality of life, and psychological health (Baer, 2003; Brown \& Ryan, 2003; Eberth \& Sedlmeier, 2012; Goyal et al., 2014; Grossman, Niemann, Schmidt, \& Walach, 2004; Khoury et al., 2015; Nyklíček \& Kuijpers, 2008; Shapiro, Schwartz, \& Santerre, 2002). Although the overall results are remarkable, it is important to have a comprehensive overview of differential effects according to individual characteristics, especially the baseline mindfulness level, to identify people who would benefit more from mindfulness-based interventions than others (Cousin \& Page, 2015).

Mindfulness-based interventions have been found to support the development of emotion regulation strategies and to reduce rumination and experiential avoidance (Chiesa, Anselmi, \& Serretti, 2014). Strategies stemming from mindfulness-based interventions, such as attentional deployment, appraisal of a situation from another perspective, and modulation of responses to events, may support emotion regulation processes (Quoidbach, Mikolajczak, \& Gross, 2015). Altogether, a mindful and accepting perspective of one's experiences could help counter negative emotions as an undoing process triggered by positive emotions (Bishop et al., 2004; Fredrickson, Mancuso, Branigan, \& Tugade, 2000). 
Self-help resources may be useful alternatives to MBSR and MBCT programs' conventional requirements (e.g. trained mindfulness practitioners, the need for participants to attend a care center several times a month, and time demands) as they may expand access to mindfulness-based strategies to a wider range of people who could potentially benefit from them (Norcross, 2006; Spijkerman, Pots, \& Bohlmeijer, 2016). Currently, many self-help resources are available to the general public, but little evidence regarding their effectiveness is available (Lever Taylor, Strauss, Cavanagh, \& Jones, 2014). Newly designed self-help tools intended to increase access to mindfulness-based therapy attempt to address traditional mindfulness group drawbacks. This specific study serves as a response to the need for empirically supported, alternative self-help therapy and tools (Kazdin \& Blase, 2011). In one study, significant effects on psychological distress were observed regardless of the length of mindfulness practice (6 or 28 hours; Carmody \& Baer, 2009). This mindfulness-based intervention included 20 minutes of formal daily practice over 42 days.

Self-help, mindfulness-based interventions have been validated in student samples (Cavanagh et al., 2013; Hazlett-Stevens \& Oren, 2017; Lever Taylor et al., 2014), the general population (Bhayee et al., 2016; Krusche, Cyhlarova, King, \& Williams, 2012; Wimberley, Mintz, \& Suh, 2016), and clinical populations (Dimidjian et al., 2014; Morledge et al., 2013). Intervention formats include workbooks (Hazlett-Stevens \& Oren, 2017; Lever Taylor et al., 2014; Wimberley et al., 2016), guided mindfulness audio recordings (Cavanagh et al., 2013; Hazlett-Stevens \& Oren, 2017; Morledge et al., 2013), websites (Cavanagh et al., 2013; Dimidjian et al., 2014; Krusche et al., 2012), and neurofeedback-assisted, technology-supported, audio-guided, in-home practice (Bhayee et al., 2016). The main outcomes include small to large improvements in mindfulness and decreases in depression, rumination, anxiety, and perceived stress, whereas control groups display no such improvements (Cavanagh et al., 2013; Dimidjian et al., 2014; Hazlett-Stevens \& Oren, 2017; Krusche et al., 2012; Lever Taylor et al., 2014; Morledge et al., 2013; Wimberley et al., 2016). One study found no statistically supported reduction in experiential avoidance (Hazlett-Stevens \& Oren, 2017). Generally, reviews and meta-analyses of self-help and online mindfulness-based interventions have revealed that these strategies are effective, with small to moderate effect sizes in decreasing anxiety, perceived stress, and depressive symptoms while increasing mindfulness skills and well-being (Cavanagh, Strauss, Forder, \& Jones, 2014; Spijkerman et al., 2016). Guided online mindfulness-based interventions were found to have stronger effects on stress reduction than unguided ones (Spijkerman et al., 2016).

Statistical investigations have shown that although aggregated inter-individual data analyses are the most widely used analyses, they do not account for intraindividual patterns of change throughout the course of a clinical intervention (Molenaar \& Campbell, 2009). A study on mindfulness intervention effects used a differential approach and found that throughout a mindfulness-based 
intervention, mindfulness levels increased less over time among individuals with higher baseline levels of mindfulness (Garland, Kiken, Faurot, Palsson, \& Gaylord, 2017). In contrast, another study found that participants with higher levels of baseline mindfulness improved more in mindfulness than those with lower baseline levels (Shapiro, Brown, Thoresen, \& Plante, 2011). Another study found that participants with higher baseline mindfulness levels adhered better to mindfulness and improved their skills more than those with low baseline levels (Kiken, Garland, Bluth, Palsson, \& Gaylord, 2015). Furthermore, mindfulness influenced the subsequent evolution of emotion regulation, psychological distress, perceived stress, and rumination (Cousin \& Page, 2015; Kiken et al., 2015; Shapiro et al., 2011). There are several possible explanations for these findings. On the one hand, individuals with higher baseline mindfulness levels may adhere more easily to mindfulness practice; they may find this experience to be simpler than people with lower baseline mindfulness levels and subsequently gain more from it. On the other hand, people with lower baseline mindfulness levels may have more room for improvement, while individuals with higher baseline levels of mindfulness may encounter ceiling effects (Shapiro et al., 2011). A differential perspective may also highlight potential negative impacts of interventions or the absence of positive impacts in some participants (Rozental et al., 2014). Perspective is important because in contrast to face-to-face psychotherapy, aversive effects and non-response may be overlooked in distant program delivery (Rozental et al., 2014). Therefore, differential analyses were conducted to fully understand the outcomes of a self-help mindfulness-based intervention.

In the present study, we offered a cost- and time-effective alternative to traditional mindfulness programs, encouraging participants' autonomy with the opportunity to participate in a plain, formal mindfulness practice project. The first aim of the study was to test the interaction effects between experimental groups and the pre-test and post-test measures. We hypothesised that compared to the control group, the participants in the mindfulness-based intervention group would demonstrate significant improvements from pre-test to post-test in affective variables such as anxiety, depression, and psychological distress and in processual variables such as mindfulness, negative self-oriented cognition, and experiential avoidance. The second aim of this study was to perform betweengroup analyses with a differential perspective. We decided to examine the potentiality for improvement and the perceived benefits of mindfulness according to a specific variable: the baseline mindfulness level of each participant. In accordance with Garland et al. (2017), we hypothesised that participants with a lower level of mindfulness at baseline would benefit from this intervention more than those with a higher baseline level of mindfulness competence. Indeed, they might experience more improvements compared to individuals starting with initial higher mindfulness levels (Shapiro et al., 2011). 


\section{METHOD}

\section{Participants}

The study participants' characteristics are shown in Table 1. One hundred and thirty participants were volunteers and agreed to take part in this study. They were recruited from December 2012 to January 2013 through written and oral announcements made by the University of Lille's students through social networks, inviting them to take some time off in order to practice mindfulness meditation at home during 6 weeks within the frame of scientific research. Participants came from a community sample of the general French population. Nighty-three participants elected to take part in the study. The inclusion criterion was at least 18 years of age, and the exclusion criteria were Axis I disorders of DSM IV, deafness, and current therapy attendance. Participants were informed of the required criteria to participate in the study through the information and consent letters. Adherence to the criteria was based on participants' disclosure. No remuneration was provided.

TABLE 1

Participants' Characteristics

\begin{tabular}{|c|c|c|c|c|c|}
\hline Variables & Value & $\begin{array}{l}\text { Control } \\
\text { group } \\
(n=44)\end{array}$ & $\begin{array}{c}\text { Mindfulness } \\
\text { group } \\
(n=47)\end{array}$ & $t$ value $(p)$ & $\begin{array}{c}\text { Chi-square } \\
(p)\end{array}$ \\
\hline Sex & Female $(\%)$ & $31(70)$ & $35(74)$ & & $0.183(.66)$ \\
\hline Age & $\begin{array}{l}\text { Mean } \\
\quad \text { (Range) }\end{array}$ & $37.6(20-80)$ & $41.4(21-67)$ & $-1.069(.28)$ & \\
\hline $\begin{array}{l}\text { Prior meditation } \\
\text { experience }\end{array}$ & Yes $(\%)$ & $21(47)$ & $26(55)$ & & $0.524(.49)$ \\
\hline $\begin{array}{l}\text { Education level: years } \\
\text { of schooling after } \\
\text { primary school }\end{array}$ & $\begin{array}{l}\text { Mean } \\
\quad(\text { Range })\end{array}$ & $8.4(0-12)$ & $8.7(4-12)$ & $1.362(.17)$ & \\
\hline \multirow[t]{3}{*}{ Activity } & $\begin{array}{l}\text { Professional } \\
(\%)\end{array}$ & $29(65.9)$ & $30(63.8)$ & & $1.245(.53)$ \\
\hline & Student $(\%)$ & $13(29.5)$ & $12(25.6)$ & & \\
\hline & Retired (\%) & $2(4.6)$ & $5(10.6)$ & & \\
\hline \multirow[t]{5}{*}{ Marital status } & $\begin{array}{l}\text { Divorced } \\
\quad(\%)\end{array}$ & 5 (11.4) & $4(8.5)$ & & $3.03(.55)$ \\
\hline & Married (\%) & $10(22.7)$ & $14(29.8)$ & & \\
\hline & Single $(\%)$ & $26(59.0)$ & $27(57.5)$ & & \\
\hline & $\begin{array}{l}\text { Civil union } \\
(\%)\end{array}$ & $2(4.6)$ & $0(0)$ & & \\
\hline & $\begin{array}{l}\text { Widowed } \\
\qquad \%)\end{array}$ & $1(2.3)$ & $2(4.2)$ & & \\
\hline
\end{tabular}




\section{ANTOINE ET AL.}

As shown in Figure 1, a total of 91 sets of data were analyzed, with 44 participants in the control group on the waiting list and 47 participants in the mindfulness group. Of the 53 participants who engaged in the mindfulness-based intervention, 92 per cent completed it; five participants dropped out of the study. Three withdrew straight after the pre-test and did not complete the MBI. One participant dropped out two days after the start of the MBI and another at the end of the first week.

Group comparisons based on the pre-test showed that all variables were equal across the groups, except for the Acting with Awareness subscale of the Five Facets of Mindfulness Questionnaire (FFMQ). The Mann-Whitney U test was

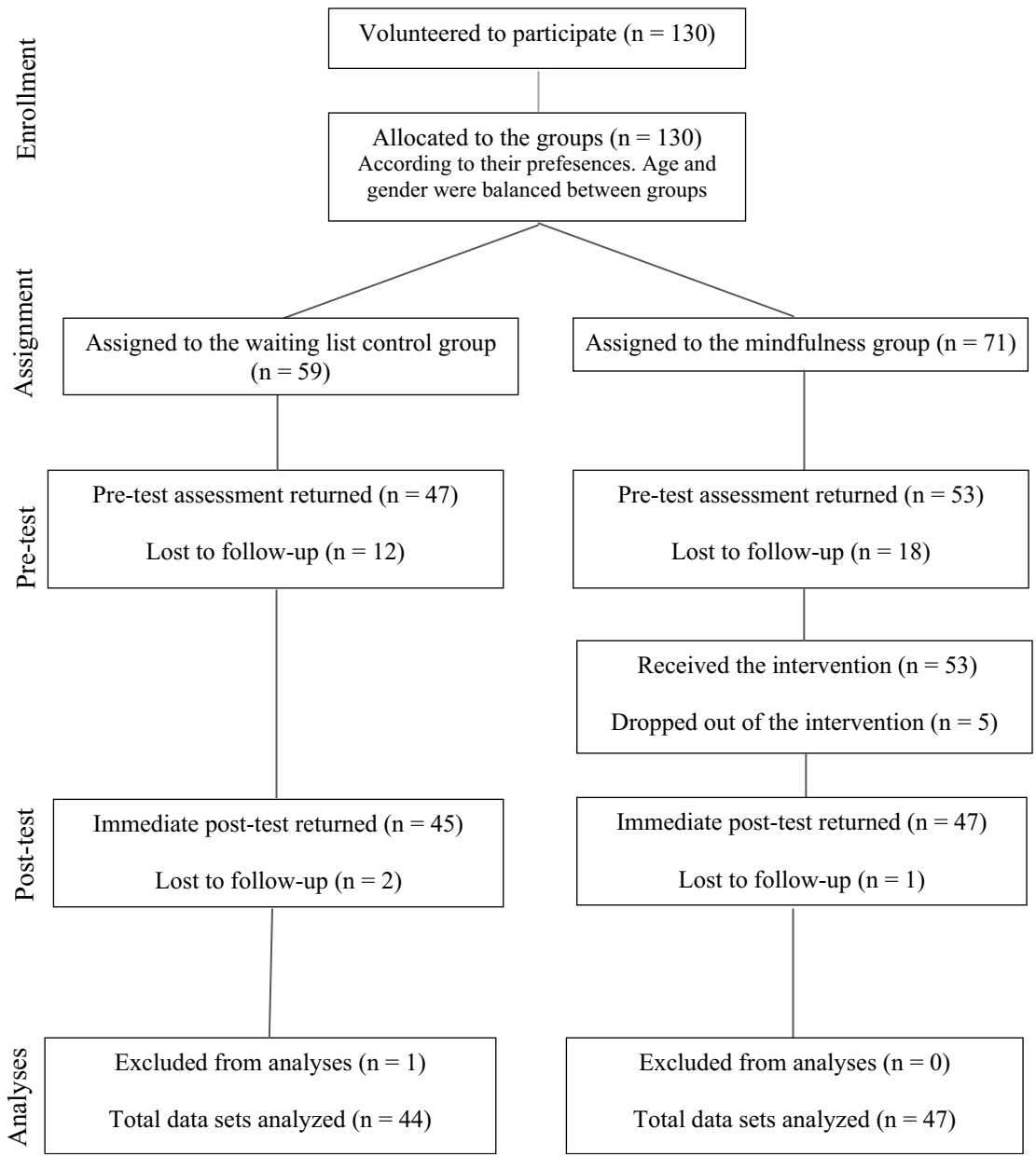

FIGURE 1. Procedure flowchart.

(C) 2018 The International Association of Applied Psychology 
used to compare the baseline data of the five participants who failed to complete the mindfulness-based intervention and the data of the remaining mindfulness group participants. The participants who quit the program were significantly younger $\left(M_{\text {year of birth }}=1988, S D_{\text {year of birth }}=5.6\right)$ and showed more putting into perspective $\left(M_{\text {perspective }}=16.6, S D_{\text {perspective }}=2.6\right)$ than those who completed it $\left(M_{\text {year of birth }}=1971, S D_{\text {year of birth }}=15.7, U=35.0, p=.01 ; M_{\text {perspective }}=12.8\right.$, $\left.S D_{\text {perspective }}=3.7, U=41.0, p=.01\right)$.

\section{Procedure}

This study was approved by the Ethical Research Committee North West III. Individuals who signed up for the study received information about the project through individual meetings, phone calls, e-mails and letters. Written informed consent was obtained from each participant included in the study. The participants were non-randomly assigned to the mindfulness and waiting list control groups according to their preferences (either whether they wished to start the intervention straight away or if they did not mind waiting 6 weeks before the intervention). Most participants had no preferences and we ensured that the two groups were appropriately balanced in terms of sex and age for comparison. Pretest baseline questionnaires were completed by all participants at the beginning of the study. Three days later, the mindfulness group participants started the 6week self-help intervention. To evaluate the participants' level of adherence, a sheet was completed daily and returned at the end of the study via the postal service in a pre-stamped envelope. Three days after the 6-week intervention ended, post-test questionnaires were completed by both the mindfulness group and the waiting list control group participants. Then, the mindfulness-based intervention was distributed to the control group participants on the waiting list. The participants who wished to be informed about the outcomes of the study were sent the results. Figure 1 shows a detailed flow chart of the experimental procedure.

Mindfulness-Based Intervention Overview. The participants received the 42-day mindfulness-based intervention program by mail, including detailed instructions and the investigators' contact information. This self-help program consisted of 20 minutes of formal mindfulness practice daily for a total of 14 hours of practice over 6 weeks. Six mindfulness practice mp3 audio recordings were displayed on a website and could be easily downloaded or were available on CD. The program included body scan practice (week 1), meditation centered on breathing (week 2), mindful walking meditation (week 3), sound meditation (week 4), meditation centered on thoughts (week 5), and finally, loving-kindness meditation (week 6). The mindfulness practices taught in previous weeks were referred to over the course of the intervention from one week to another. The design of the mindfulness-based program was created with the help of two trained mindfulness practitioners. 


\section{Measures}

Socio-demographic variables: The participants' age, sex, family situation and education level as well as their previous mindfulness practice experience were recorded from a questionnaire.

Adherence: A sheet was completed daily by the participants to evaluate whether they had completed their mindfulness practice. Adherence scores were computed based on this sheet.

Mindfulness: The French version of the Mindful Attention Awareness Scale (Brown \& Ryan, 2003; Jermann et al., 2009) was used to evaluate attention and present-moment awareness. This 15 -item scale is based on a unidimensional concept of mindfulness. On a 6-point Likert scale ranging from 1 (almost always) to 6 (almost never), the participants indicated their perceived frequency of several daily life experiences. Higher scores represent higher levels of mindfulness. This scale was validated with an internal consistency of .84 (Jermann et al., 2009), and Cronbach's alpha in this study sample was .87.

The French version of the Five Facet Mindfulness Questionnaire (Baer et al., 2008), validated by Heeren, Douilliez, Peschard, Debrauwere, and Philippot (2011), was used to assess changes in the participants' mindfulness skills in daily life. This 39-item questionnaire addresses five facets of mindfulness derived from a factor analysis: observing, describing, acting with awareness, non-judging of inner experiences, and non-reactivity to inner experiences. On a 5-point Likert scale ranging from 1 (hardly ever true) to 5 (very often true), the participants rated the degree to which each statement was true for them. In the French version, Cronbach's alpha for each dimension is greater than .76 (Heeren et al., 2011), and it was greater than .80 in this sample.

Affective and processual variables: The French translation of the 20-item Spielberger State-Trait Anxiety Inventory (STAI; Spielberger, Gorsuch, \& Lushene, 1970; Gauthier \& Bouchard, 1993) was used to assess trait anxiety levels. Responses were given on a 4-point scale ranging from 1 (never) to 4 (always). Trait anxiety refers to the frequency and tendency to regard the environment as a threat. Internal consistency reliability was $\alpha=.91$ for the French-validated traitanxiety scale (Gauthier \& Bouchard, 1993) and in this sample.

The 13-item French version of the Beck Depression Inventory - Short Form (Beck \& Beamesderfer, 1974; Bourque \& Beaudette, 1982) was used to assess various aspects of depressive symptomatology. The participants chose one of three statements that most closely matched their current state of mind. Responses to this questionnaire are rated on a 4-point scale from 0 (none) to 3 (severe depressive symptoms). Internal consistency reliability was $\alpha=.90$ (Bourque \& Beaudette, 1982). Cronbach's alpha in this study was .82 .

The seven-item Acceptance and Action Questionnaire (AAQ-II; Bond et al., 2011) measures the extent to which participants display experiential avoidance of negative events or try to control unpleasant internal events. We used the French- 
validated version, which has an internal consistency of $\alpha=.83$ (Monestès, Villatte, Mouras, Loas, \& Bond, 2009), and Cronbach's alpha was .89 in this sample.

The General Health Questionnaire - 12 (GHQ-12; Goldberg et al., 1997) is intended to screen for psychological morbidity and distress and to detect emergent psychiatric disorders. This self-report questionnaire measures the frequency with which participants experienced different symptoms, with a list of 12 items, in recent weeks on a 4-point scale. This questionnaire was validated in French by Salama-Younes, Montazeri, Ismail, and Roncin (2009), with an internal consistency of .78. Cronbach's alpha in this study was .85.

The Automatic Thoughts Questionnaire (Hollon \& Kendall, 1980) is a 30-item scale measuring the frequency of negative thoughts as self-statements in the past week, rated from 1 (not at all) to 5 (all the time). The French version was validated by Bouvard, Charles, Mollard, Guérin, and Cottraux (1992), with an internal consistency of .91. Cronbach's alpha in this study was .95 .

\section{Statistical Analysis}

The data were analyzed with $\mathrm{R}$ software (version 3.1.2) for Windows. The self-assessment data included levels of anxiety, depression, psychological distress, mindfulness, negative self-oriented cognition, and experiential avoidance. Ninety-one data sets were examined, including 47 in the mindfulness group and 44 in the control group on the waiting list (see Figure 1). Due to missing responses, one data set was withdrawn from the waiting list control group and one was excluded from the mindfulness group for the analysis. To compare pre-test socio-demographic and baseline variables between the experimental groups, chi-square and between-group two-tailed $t$-tests were conducted (see Table 1 and Table 2). In order to compare the mindfulness group and the five participants who dropped out of the intervention a Mann-Whitney U test was conducted. Repeated-measures analysis of variance (ANOVA) was performed to study the interaction effects between the experimental groups and the pre-test and post-test measures. Effect sizes were computed to rate the significance of the intervention's impact on several variables. Analyses of intra-individual differences in the variables were performed with a generalised linear model (GLM).

\section{RESULTS}

\section{Adherence to the $\mathrm{MBI}$}

In the mindfulness group, the participants completed an average of 39 guided mindfulness practices out of $42(S D=3.9, \min =26, \max =42)$. 


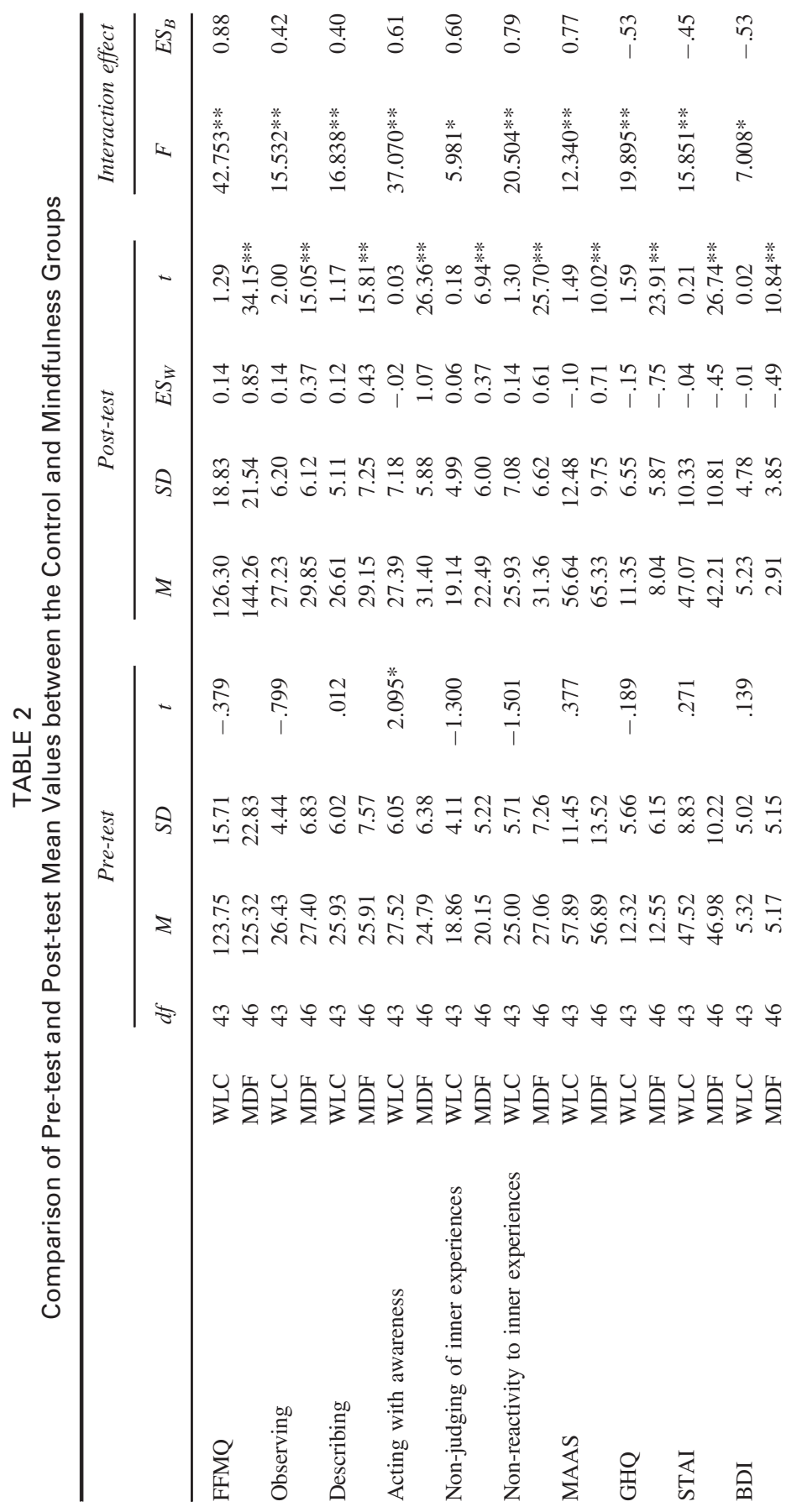




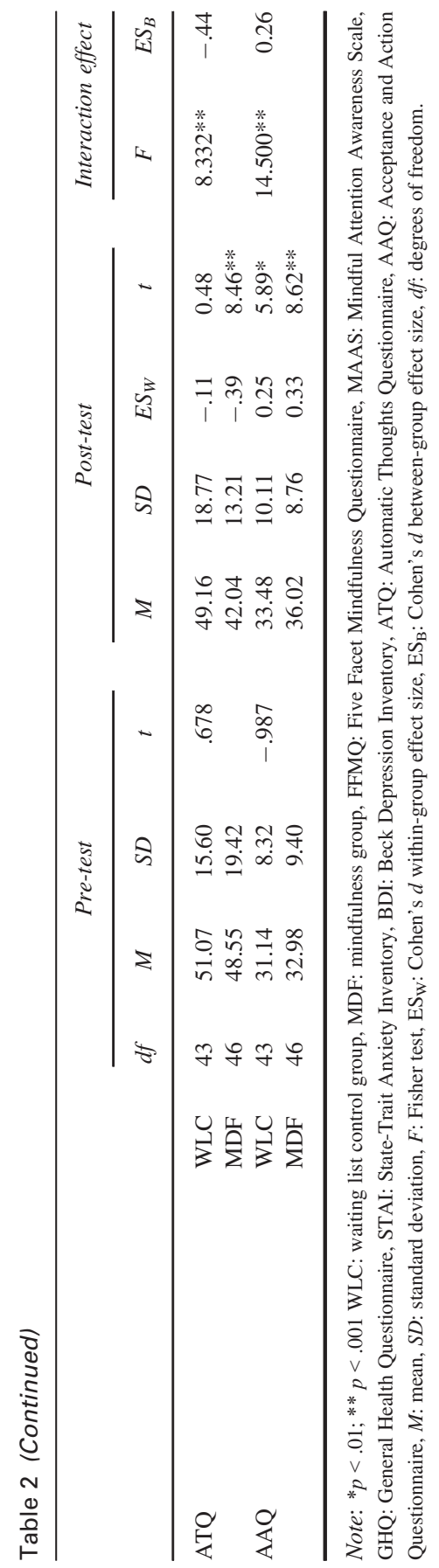

(C) 2018 The International Association of Applied Psychology 


\section{Individual Differences in Mindfulness-Based Intervention Effects}

As Table 2 shows, the pre-test and post-test comparisons for the two groups appeared to be significant for all variables, highlighting the program's impact on affective and functioning variables. Indeed, anxiety and depression scores evolved with small to medium effect sizes. Psychological distress decreased with a medium to large effect size. Mindfulness increased with a large effect size, while negative self-oriented cognitions and experiential avoidance decreased with small effect sizes.

\section{Mindfulness-Based Intervention Processual Evolution and Individual Differences}

Whether participants with specific profiles benefited more from the mindfulnessbased intervention based on their baseline mindfulness competencies was investigated. Our hypothesis was that the participants who already demonstrated high levels of mindfulness would benefit less from this type of intervention than those who did not. For a more precise understanding of the results from a differential perspective, GLMs were modeled based on all significant variables (see Table 2). The aims of the analysis were to compare pre-test and post-test mindfulness levels between the two groups according to the baseline level of each variable, and then to observe differential effects based on individuals' baseline levels.

The graph on the left of Figure 2 shows individual Mindful Attention Awareness Scale (MAAS) standardised pre-test scores (T1) on the X-axis and post-test scores (T2) on the y-axis. Each dot represents a participant: gray dots represent waiting list control group participants and black dots represent mindfulness group participants. In such a graph, if the intervention had no effect, then all the dots would be around the diagonal, dotted, light gray line, revealing identical scores before and after the mindfulness-based intervention. The participants whose dots are under the diagonal dotted line had decreased scores from pre-test to post-test. Most black dots are above the diagonal dotted line, indicating that the participants in the mindfulness group scored better on the MAAS after the intervention than before.

GLM modeling allows for a linear regression representation of the waiting list control group (gray line) and the mindfulness group (black line), allowing observation of the participants' reactions throughout the course of the intervention. The waiting list control group line is below the diagonal dotted line, reflecting decreases in MAAS scores. By contrast, the black line is above this line, reflecting significant increases in MAAS scores with mindfulness practice. A significant interaction effect was found between pre-test MAAS levels and post-test MAAS levels $(r=-0.55, p<.001)$. Therefore, mindfulness in daily life 

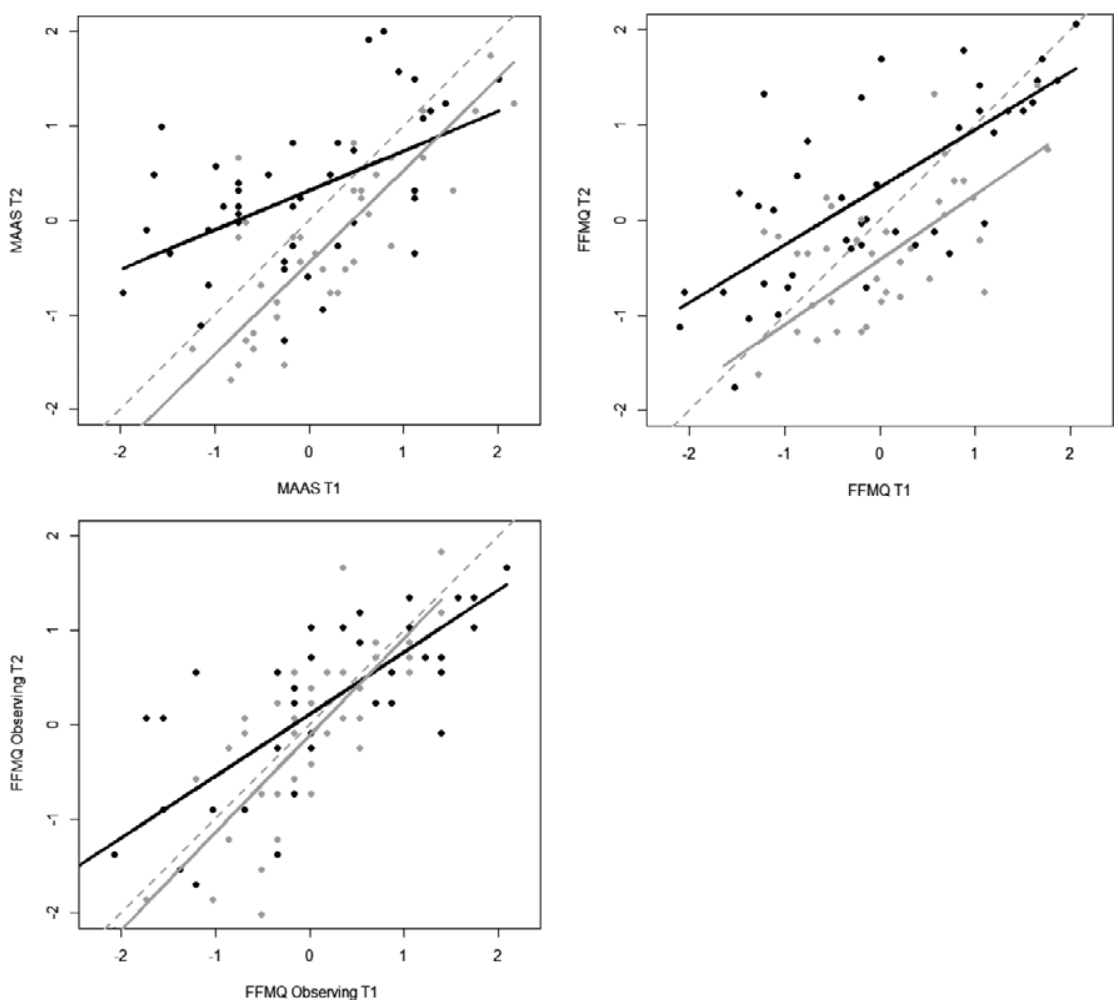

FIGURE 2. Graphic GLM representation of the MAAS, FFMO, and FFMO subscale observing at pre-test (T1) and post-test (T2).

Note: Each participant is represented by a dot. Gray dots represent the waiting list control group participants, and black dots represent the mindfulness group participants. The diagonal, dotted, light gray line indicates an identical score before and after the mindfulness-based intervention. The participants whose dots are above the diagonal dotted line had increased scores from pre-test to post-test. The gray and black lines are linear regression lines of the waiting list control and mindfulness groups, respectively. A line below the diagonal dotted line indicates that scores decreased over time, whereas a line above the diagonal dotted line indicates that scores increased from pre-test to post-test.

increased even more throughout the mindfulness-based intervention for the people with low baseline mindfulness competencies. The black line's steepest slope illustrates this phenomenon well.

On the other hand, the graph on the right shows the results for overall FFMQ scores. As shown, the mindfulness group participants with low baseline FFMQ scores progressed more in this dimension than the participants with higher 
baseline scores. However, this effect was also observed in the waiting list control group. Therefore, the interaction effect is not significant for overall FFMQ scores $(r=-0.07, p=.635)$.

Notably, from a descriptive perspective, the participants with lower MAAS levels $(-2)$ progressed to a level of -0.5 , representing a +1.5 -standard deviation increase, which is twice the average Cohen's $d$ observed. In addition, FFMQ scores increased by 1 standard deviation among the individuals who initially showed lower levels of mindfulness. Nevertheless, a closer look at the FFMQ subscales reveals significant interaction effects for the observing $(r=-0.37, p=$ $.011,<0.05)$ subscale, as shown in Figure 2. No significant interaction effects were found for the other subscales of describing $(r=0.15, p=.339)$, nonjudging of inner experiences $(r=-0.25, p=.117)$, acting with awareness $(r=$ $-0.09, p=.563)$, and non-reactivity $(r=-0.06, p=.706)$. The participants who exhibited a low observing level at baseline benefited more from the mindfulnessbased intervention in developing mindfulness competence.

\section{DISCUSSION}

Mindfulness, as a formal practice, was the core of this approach. The participants had autonomous access to daily 20-minute mindfulness practice over 42 days. Significant results were found in this intervention study, although the constitutive elements usually found in group mindfulness-based interventions - such as peer influence, trained mindfulness professional support, and didactic content (Bhayee et al., 2016) - were not introduced. Indeed, mindfulness practice resulted in several positive findings related to affective and functioning variables.

This study's findings appear consistent with those in the literature regarding self-help, mindfulness-based interventions - especially the significant improvements in mindfulness, anxiety, depression, psychological distress, and negative self-oriented cognition throughout the program in the intervention condition but not in the control condition - and the effect sizes were similar to or slightly better than those found in the literature (Cavanagh et al., 2013; Dimidjian et al., 2014; Hazlett-Stevens \& Oren, 2017; Lever Taylor et al., 2014; Morledge et al., 2013; Spijkerman et al., 2016; Wimberley et al., 2016). The results also revealed significant improvements in experiential avoidance, indicating that emotional functioning changed in the experimental group but not in the control group on the waiting list. Formal mindfulness implementation in the participants' daily routines appeared to be easy and feasible, with satisfactory adherence as 90 per cent of the participants completed the program in contrast to the observations of Hazlett-Stevens and Oren (2017) in their student population. Within the current study design, the participants could not benefit from therapy support, incentives, and feedback regarding their practice from the investigators. However, it seemed that clinical mediation was not necessary to experience significant changes; in this study commitment to mindfulness practice appeared to be sufficient. 
In this study, the mindfulness group, unlike the waiting list control group, reported significant improvements in all FFMQ subscales with large effect sizes. On the contrary, Lever Taylor et al. (2014), who conducted an 8-week program based on a series of 20- to 30-minute mindfulness practices and on a mindfulness cognitive therapy book, did not find any change in the describing subscale with their intervention. In addition, Haenen, Nyklíček, van Son, Pop, and Pouwer's (2016) program that consisted of 8 weeks of mindfulness-based cognitive group therapy saw changes in observing, acting with awareness, and non-reactivity to inner experiences scores in their mindfulness group - such discrepancies between interventions may be explained by the content of the mindfulness-based interventions (i.e. type of support such as book or audio guidance, group or individual setting). Furthermore, FFMQ facets have been found to evolve consistently with the amount of formal in-home mindfulness practice reported by participants (all but not describing; Carmody \& Baer, 2008), but not at the same time (Baer et al., 2012).

Previously performed mindfulness-based interventions reported the mindfulness-mediating intervention's impact on depression, anxiety, and perceived stress (Baer, Walsh, \& Lykins, 2009; Batink, Peeters, Geschwind, van Os, \& Wichers, 2013; Gu, Strauss, Bond, \& Cavanagh, 2015; Haenen et al., 2016). Moreover, mindfulness interventions have been recognised as playing a significant role in reducing rumination and experiential avoidance, subsequently resulting in decreased depressive symptoms (Chiesa et al., 2014). Although we did not explore such relationships in this study, our observations regarding the depression, anxiety, and perceived stress variables may have stemmed from this mediating effect.

The findings in this study included a reduction in experiential avoidance, which is consistent with the findings reported by Chiesa et al. (2014) but contradicts Hazlett-Stevens and Oren's (2017) bibliotherapy mindfulness-based intervention outcomes. Psychological flexibility, as opposed to experiential avoidance, was found to be a significant mediator of mindfulness-based intervention effects on perceived stress (Gu et al., 2015). Although further investigation is required, our results may indicate that mindfulness is an experience that promotes a potential shift in an individual's experiential approach, providing possible evidence of reactivity mitigation during current events, which is consistent with Shapiro, Carlson, Astin, and Freedman's (2006) theoretical approach. The effects of mindfulness may be enhanced by several processes that were not assessed in this study, including decentering that was identified by Feldman, Greeson, and Senville (2010) and Shapiro et al. (2006) as a core mechanism. Attending to cognition as part of a mindful internal experience could help in the development of awareness of repetitive thoughts and lead to exposure and habituation processes, which may contribute to emotional processing and reduce the impact of repetitive thoughts (Feldman et al., 2010; Shapiro et al., 2006). This approach may be related to our observations with the automatic thoughts 
questionnaire measures; such thoughts decreased significantly from pre-test to post-test in the mindfulness condition. Repetitive negative thinking was found to be a significant mediator of mindfulness-based intervention effects on clinical variables such as depressive affect, anxiety, and perceived stress ( $\mathrm{Gu}$ et al., 2015).

The differential perspective of this study allowed us to observe that the participants with lower pre-test levels of mindfulness experienced a significant increase in mindful attention in their daily life over the course of the program, which is consistent with Garland et al. (2017). Although this tendency was significant for the MAAS, only the observing subscale of the FFMQ showed similar outcomes. Accordingly, the individuals with lower scores on the MAAS and the observing subscale at baseline showed greater increases in these variables, which may be explained by a larger improvement range for individuals scoring low on these variables at baseline than for others (Shapiro et al., 2011). Therefore, mindfulness practice may be recommended for a population with such initial characteristics. The overall FFMQ scores did not appear to evolve because the waiting list control group exhibited the same pattern as the mindfulness group. Surprisingly, the acting with awareness subscale, which features items similar to those in the MASS (Baer, Smith, Hopkins, Krietemeyer, \& Toney, 2006), did not reveal equivalent outcomes; however, equivalencies at pre-test were not found between the groups for this variable. Such discrepancies in subscale evolution according to the participants' baseline levels may have resulted from the descriptions of the questionnaires' items. Indeed, the MAAS and the observing FFMQ subscale include practical examples that individuals could identify with. Moreover, the content of this mindfulness-based intervention may have also influenced outcomes as it was entirely composed of formal practices; informal activities were not emphasised. As formal and informal mindfulness training may not trigger similar effects (Hindman, Glass, Arnkoff, \& Maron, 2015), a visible tendency in the mindfulness questionnaire outcomes could have emerged. For instance, if the intervention had suggested informal descriptive activities, the baseline describing level could have influenced its subsequent progression.

This study was conducted on a community sample of the French population without psychopathological or health issues. As the participants voluntarily took part in this intervention, the inclusion process may reflect a self-selection bias (involving an intentional stage) based on mindfulness implementation according to Shapiro et al. (2006). Moreover, the lack of strict randomisation limits the generality of the findings. Since the participants came from a healthy community sample, their baseline scores for symptom expression are likely to be lower than those of a clinical population, which may have led to less meaningful improvements. Consequently, the smallest effect sizes found in our study may depict a floor effect, as Spijkerman et al. (2016) noted in their study. Several limitations are inherent in the use of scales and questionnaires. Grossman and Van Dam (2011) emphasised that questionnaires used to measure mindfulness may reflect 
a lack of mindfulness - that is, mindlessness and unawareness. As the data were obtained through self-assessment, they were subject to social desirability effects. Regarding our study design, the control group was on a waiting list. Future research could consider adding an active control condition to expand the improvement range and could also include active control participants. We did not conduct medium- or long-term follow-ups. Such investigations are required to better understand the extent to which mindfulness is implemented in participants' daily life and should be part of future studies. In addition, many trials have developed their own MBI, leading to a variety in content across interventions, which impairs the generalisation of the findings. Future research might also address this problem.

Self-help interventions offer cost-effective access to mindfulness resources and can reach individuals who may be seeking alternatives to more traditional approaches, such as group or one-to-one sessions (Cavanagh et al., 2014). Validated self-help approaches could be effective strategies to expand upon work carried out in therapy sessions with clinicians if the effects are supported. In addition, these self-help interventions could be recommended to individuals on a waiting list for psychological treatment (Norcross, 2006). From this clinical perspective, it would be interesting for future investigations to explore whether this self-help, 20-minutes-a-day, mindfulness-based intervention could be adjusted for clinical populations in health and psychiatric fields.

The appropriate amount of mindfulness practice remains uncertain, which should be investigated further so that future mindfulness interventions can be even more specific in terms of session length and the number of days necessary to achieve significant changes (Bhayee et al., 2016; Hazlett-Stevens \& Oren, 2017). The characteristics of individuals who enroll and complete mindfulnessbased interventions should also be explored. Evaluating baseline characteristics to identify predictive variables for beneficial clinical outcomes in terms of health and well-being and to specify clinical interventions would be interesting. We found that novice meditators showed significant improvements on the observing subscale. Different types of mindfulness, from formal to informal practice, could be evaluated in a future study targeting other facets and differentiating effective strategies to cultivate mindfulness according to individuals' needs and initial dispositions (Hindman et al., 2015). Determining the underlying mechanisms of mindfulness-based interventions is also necessary to develop interventions that meet specific needs, to identify triggers of potential effects, and to enhance specific components to better suit individual objectives ( $\mathrm{Gu}$ et al., 2015). Mediation and moderation analyses could be performed to elucidate mindfulness processes of change, which may require larger samples. In contrast, adhesion and attrition measures could help us better understand the conditions under which people cannot benefit from mindfulness-based interventions.

Altogether, this study illustrated how daily 20-minute formal mindfulness practice over 6 weeks could enhance positive outcomes for affective variables 
and contribute to positive emotional functioning. This study also showed that participants with low baseline mindfulness levels could benefit more from a mindfulness-based intervention than those with high baseline levels. Future research should continue to investigate differential aspects related to positive impacts and should also consider impairments associated with intervention evaluation. In doing so, individuals may be referred by clinicians to more appropriate and effective interventions that suit their needs according to their characteristics.

\section{COMPLIANCE WITH ETHICAL STANDARDS}

All procedures performed in studies involving human participants were conducted in accordance with the ethical standards of the national research committee and the 1964 Helsinki Declaration and its later amendments or comparable ethical standards.

\section{CONFLICT OF INTEREST}

The authors declare no conflicts of interest regarding the authorship and publication of this article.

\section{REFERENCES}

Baer, R.A. (2003). Mindfulness training as a clinical intervention: A conceptual and empirical review. Clinical Psychology: Science and Practice, 10(2), 125-143.

Baer, R.A., Carmody, J., \& Hunsinger, M. (2012). Weekly change in mindfulness and perceived stress in a mindfulness-based stress reduction program. Journal of Clinical Psychology, 68(7), 755-765. https://doi.org/10.1002/jclp.21865.

Baer, R.A., Smith, G.T., Hopkins, J., Krietemeyer, J., \& Toney, L. (2006). Using selfreport assessment methods to explore facets of mindfulness. Assessment, 13(1), 27-45. https://doi.org/10.1177/1073191105283504.

Baer, R.A., Smith, G.T., Lykins, E., Button, D., Krietemeyer, J., Sauer, S., et al. (2008). Construct validity of the Five Facet Mindfulness Questionnaire in meditating and nonmeditating samples. Assessment, 15(3), 329-342. https://doi.org/10.1177/1073191107 313003.

Baer, R.A., Walsh, E., \& Lykins, E. (2009). Assessment of mindfulness. In D. Fabrizio (Ed.), Clinical handbook of mindfulness (pp. 153-168). New York: Springer.

Batink, T., Peeters, F., Geschwind, N., van Os, J., \& Wichers, M. (2013). How does MBCT for depression work? Studying cognitive and affective mediation pathways. PLoS ONE, 8(8), e72778. https://doi.org/10.1371/journal.pone.0072778.

Beck, A.T., \& Beamesderfer, A. (1974). Assessment of depression: The depression inventory. Basel: Karger Publishers.

Bhayee, S., Tomaszewski, P., Lee, D.H., Moffat, G., Pino, L., Moreno, S., et al. (2016). Attentional and affective consequences of technology supported mindfulness training: 
A randomised, active control, efficacy trial. BMC Psychology, 4(1), 60. https://doi.org/ 10.1186/s40359-016-0168-6.

Bishop, S.R., Lau, M., Shapiro, S., Carlson, L., Anderson, N.D., Carmody, J., et al. (2004). Mindfulness: A proposed operational definition. Clinical Psychology: Science and Practice, 11(3), 230-241. https://doi.org/10.1093/clipsy.bph077.

Bond, F.W., Hayes, S.C., Baer, R.A., Carpenter, K.M., Guenole, N., Orcutt, H.K., et al. (2011). Preliminary psychometric properties of the Acceptance and Action Questionnaire-II: A revised measure of psychological inflexibility and experiential avoidance. Behavior Therapy, 42(4), 676-688.

Bourque, P., \& Beaudette, D. (1982). Étude psychometrique du questionnaire de dépression de Beck auprès d'un échantillon d'étudiants universitaires francophones. Canadian Journal of Behavioural Science/Revue Canadienne des Sciences du Comportement, 14(3), 211-218.

Bouvard, M., Charles, S., Mollard, E., Guérin, J., \& Cottraux, J. (1992). Étude de validation et analyse factorielle de la version française du questionnaire des pensées automatiques. Journal de Thérapie Comportementale et Cognitive, 2, 25-28.

Brown, K.W., \& Ryan, R.M. (2003). The benefits of being present: Mindfulness and its role in psychological well-being. Journal of Personality and Social Psychology, 84(4), 822-848. https://doi.org/10.1037/0022-3514.84.4.822.

Carmody, J., \& Baer, R.A. (2008). Relationships between mindfulness practice and levels of mindfulness, medical and psychological symptoms and well-being in a mindfulness-based stress reduction program. Journal of Behavioral Medicine, 31(1), 23-33. https://doi.org/10.1007/s10865-007-9130-7.

Carmody, J., \& Baer, R.A. (2009). How long does a mindfulness-based stress reduction program need to be? A review of class contact hours and effect sizes for psychological distress. Journal of Clinical Psychology, 65(6), 627-638. https://doi.org/10.1002/jclp. 20555.

Cavanagh, K., Strauss, C., Cicconi, F., Griffiths, N., Wyper, A., \& Jones, F. (2013). A randomised controlled trial of a brief online mindfulness-based intervention. Behaviour Research and Therapy, 51(9), 573-578. https://doi.org/10.1016/j.brat.2013. 06.003 .

Cavanagh, K., Strauss, C., Forder, L., \& Jones, F. (2014). Can mindfulness and acceptance be learnt by self-help? A systematic review and meta-analysis of mindfulness and acceptance-based self-help interventions. Clinical Psychology Review, 34(2), 118 129. https://doi.org/10.1016/j.cpr.2014.01.001.

Chiesa, A., Anselmi, R., \& Serretti, A. (2014). Psychological mechanisms of mindfulness-based interventions: What do we know? Holistic Nursing Practice, 28(2), 124 148. https://doi.org/10.1097/HNP.0000000000000017.

Chiesa, A., \& Serretti, A. (2009). Mindfulness-based stress reduction for stress management in healthy people: A review and meta-analysis. Journal of Alternative and Complementary Medicine, 15(5), 593-600.

Cousin, G., \& Page, D. (2015). Does patients' pretreatment trait-mindfulness predict the success of cognitive psychotherapy for emotion regulation? Mindfulness, 6(2), 186191. https://doi.org/10.1007/s12671-013-0243-5.

Dimidjian, S., Beck, A., Felder, J.N., Boggs, J.M., Gallop, R., \& Segal, Z.V. (2014). Web-based mindfulness-based cognitive therapy for reducing residual depressive 
symptoms: An open trial and quasi-experimental comparison to propensity score matched controls. Behaviour Research and Therapy, 63, 83-89. https://doi.org/10. 1016/j.brat.2014.09.004.

Eberth, J., \& Sedlmeier, P. (2012). The effects of mindfulness meditation: A meta-analysis. Mindfulness, 3(3), 174-189. https://doi.org/10.1007/s12671-012-0101-x.

Feldman, G., Greeson, J., \& Senville, J. (2010). Differential effects of mindful breathing, progressive muscle relaxation, and loving-kindness meditation on decentering and negative reactions to repetitive thoughts. Behaviour Research and Therapy, 48(10), 1002-1011. https://doi.org/10.1016/j.brat.2010.06.006.

Fredrickson, B.L., Mancuso, R.A., Branigan, C., \& Tugade, M.M. (2000). The undoing effect of positive emotions. Motivation and Emotion, 24(4), 237-258.

Garland, E.L., Kiken, L.G., Faurot, K., Palsson, O., \& Gaylord, S.A. (2017). Upward spirals of mindfulness and reappraisal: Testing the mindfulness-to-meaning theory with autoregressive latent trajectory modeling. Cognitive Therapy and Research, 41(3), 381-392. https://doi.org/10.1007/s10608-016-9768-y.

Gauthier, J., \& Bouchard, S. (1993). Adaptation canadienne-française de la forme révisée du State-Trait Anxiety Inventory de Spielberger. Canadian Journal of Behavioural Science/Revue Canadienne des Sciences du Comportement, 25(4), 559-578. https://d oi.org/10.1037/h0078881.

Goldberg, D.P., Gater, R., Sartorius, N., Ustun, T., Piccinelli, M., Gureje, O., et al. (1997). The validity of two versions of the GHQ in the WHO study of mental illness in general health care. Psychological Medicine, 27(01), 191-197.

Goyal, M., Singh, S., Sibinga, E.M.S., Gould, N.F., Rowland-Seymour, A., Sharma, R., et al. (2014). Meditation programs for psychological stress and well-being: A systematic review and meta-analysis. JAMA Internal Medicine, 174(3), 357-368. https://doi. org/10.1001/jamainternmed.2013.13018.

Greco, L.A., Baer, R.A., \& Smith, G.T. (2011). Assessing mindfulness in children and adolescents: Development and validation of the Child and Adolescent Mindfulness Measure (CAMM). Psychological Assessment, 23(3), 606-614. https://doi.org/10. 1037/a0022819.

Grossman, P., Niemann, L., Schmidt, S., \& Walach, H. (2004). Mindfulness-based stress reduction and health benefits. Journal of Psychosomatic Research, 57(1), 35-43. https://doi.org/10.1016/S0022-3999(03)00573-7.

Grossman, P., \& Van Dam, N.T. (2011). Mindfulness, by any other name...: Trials and tribulations of sati in western psychology and science. Contemporary Buddhism, 12 (1), 219-239. https://doi.org/10.1080/14639947.2011.564841.

Gu, J., Strauss, C., Bond, R., \& Cavanagh, K. (2015). How do mindfulness-based cognitive therapy and mindfulness-based stress reduction improve mental health and wellbeing? A systematic review and meta-analysis of mediation studies. Clinical Psychology Review, 37, 1-12. https://doi.org/10.1016/j.cpr.2015.01.006.

Haenen, S., Nyklíček, I., van Son, J., Pop, V., \& Pouwer, F. (2016). Mindfulness facets as differential mediators of short and long-term effects of Mindfulness-Based Cognitive Therapy in diabetes outpatients: Findings from the DiaMind randomized trial. Journal of Psychosomatic Research, 85, 44-50. https://doi.org/10.1016/j.jpsychores. 2016.04.006. 
Hazlett-Stevens, H., \& Oren, Y. (2017). Effectiveness of mindfulness-based stress reduction bibliotherapy: A preliminary randomized controlled trial. Journal of Clinical Psychology, 73(6), 626-637. https://doi.org/10.1002/jclp.22370.

Heeren, A., Douilliez, C., Peschard, V., Debrauwere, L., \& Philippot, P. (2011). Crosscultural validity of the Five Facets Mindfulness Questionnaire: Adaptation and validation in a French-speaking sample. Revue Européenne de Psychologie Appliquéel European Review of Applied Psychology, 61(3), 147-151. https://doi.org/10.1016/j.era p.2011.02.001.

Hindman, R.K., Glass, C.R., Arnkoff, D.B., \& Maron, D.D. (2015). A comparison of formal and informal mindfulness programs for stress reduction in university students. Mindfulness, 6(4), 873-884. https://doi.org/10.1007/s12671-014-0331-1.

Hofmann, S.G., Sawyer, A.T., Witt, A.A., \& Oh, D. (2010). The effect of mindfulnessbased therapy on anxiety and depression: A meta-analytic review. Journal of Consulting and Clinical Psychology, 78(2), 169-183. https://doi.org/10.1037/ a0018555.

Hollon, S.D., \& Kendall, P.C. (1980). Cognitive self-statements in depression: Development of an automatic thoughts questionnaire. Cognitive Therapy and Research, 4(4), 383-395.

Jermann, F., Billieux, J., Larøi, F., d'Argembeau, A., Bondolfi, G., Zermatten, A., et al. (2009). Mindful Attention Awareness Scale (MAAS): Psychometric properties of the French translation and exploration of its relations with emotion regulation strategies. Psychological Assessment, 21(4), 506-514. https://doi.org/10.1037/a0017032.

Kabat-Zinn, J. (1990). Full catastrophe living: Using the wisdom of your body and mind to face stress, pain, and illness. New York: Delta.

Kabat-Zinn, J. (1996). Mindfulness meditation: What it is, what it isn't, and its role in health care and medicine. In Y. Haruki, Y. Ishii, \& M. Suzuki (Eds.), Comparative and psychological study on meditation (pp. 161-169). Delft, the Netherlands: Eburon.

Kazdin, A.E., \& Blase, S.L. (2011). Rebooting psychotherapy research and practice to reduce the burden of mental illness. Perspectives on Psychological Science, 6(1), 2137. https://doi.org/10.1177/1745691610393527.

Khoury, B., Sharma, M., Rush, S.E., \& Fournier, C. (2015). Mindfulness-based stress reduction for healthy individuals: A meta-analysis. Journal of Psychosomatic Research, 78(6), 519-528. https://doi.org/10.1016/j.jpsychores.2015.03.009.

Kiken, L.G., Garland, E.L., Bluth, K., Palsson, O.S., \& Gaylord, S.A. (2015). From a state to a trait: Trajectories of state mindfulness in meditation during intervention predict changes in trait mindfulness. Personality and Individual Differences, 81, 41-46. https://doi.org/10.1016/j.paid.2014.12.044.

Krusche, A., Cyhlarova, E., King, S., \& Williams, J.M.G. (2012). Mindfulness online: A preliminary evaluation of the feasibility of a web-based mindfulness course and the impact on stress. BMJ Open, 2(3), e000803. https://doi.org/10.1136/bmjopen-2011000803.

Lever Taylor, B., Strauss, C., Cavanagh, K., \& Jones, F. (2014). The effectiveness of selfhelp mindfulness-based cognitive therapy in a student sample: A randomised controlled trial. Behaviour Research and Therapy, 63, 63-69. https://doi.org/10.1016/j.bra t.2014.09.007. 
Molenaar, P.C., \& Campbell, C.G. (2009). The new person-specific paradigm in psychology. Current Directions in Psychological Science, 18(2), 112-117.

Monestès, J.-L., Villatte, M., Mouras, H., Loas, G., \& Bond, F.W. (2009). Traduction et validation française du questionnaire d'acceptation et d'action (AAQ-II). Revue Européenne de Psychologie Appliquée/European Review of Applied Psychology, 59 (4), 301-308. https://doi.org/10.1016/j.erap.2009.09.001.

Morledge, T.J., Allexandre, D., Fox, E., Fu, A.Z., Higashi, M.K., Kruzikas, D.T., et al. (2013). Feasibility of an online mindfulness program for stress management-A randomized, controlled trial. Annals of Behavioral Medicine, 46(2), 137-148. https://doi. org/10.1007/s12160-013-9490-x.

Norcross, J.C. (2006). Integrating self-help into psychotherapy: 16 practical suggestions. Professional Psychology: Research and Practice, 37(6), 683-693. https://doi.org/10. 1037/0735-7028.37.6.683.

Nyklíček, I., \& Kuijpers, K.F. (2008). Effects of mindfulness-based stress reduction intervention on psychological well-being and quality of life: Is increased mindfulness indeed the mechanism? Annals of Behavioral Medicine, 35(3), 331-340. https://doi. org/10.1007/s12160-008-9030-2.

Quoidbach, J., Mikolajczak, M., \& Gross, J.J. (2015). Positive interventions: An emotion regulation perspective. Psychological Bulletin, 141(3), 655-693. https://doi.org/10. 1037/a0038648.

Rozental, A., Andersson, G., Boettcher, J., Ebert, D.D., Cuijpers, P., Knaevelsrud, C., et al. (2014). Consensus statement on defining and measuring negative effects of Internet interventions. Internet Interventions, 1(1), 12-19. https://doi.org/10.1016/j.invent. 2014.02.001.

Salama-Younes, M., Montazeri, A., Ismail, A., \& Roncin, C. (2009). Factor structure and internal consistency of the 12-item General Health Questionnaire (GHQ-12) and the Subjective Vitality Scale (VS), and the relationship between them: A study from France. Health and Quality of Life Outcomes, 7(1), 22. https://doi.org/10.1186/14777525-7-22.

Segal, Z.V., Williams, J.M.G., \& Teasdale, J.D. (2002). Mindfulness-based cognitive therapy for depression: A new approach to relapse prevention. New York: Guilford.

Shapiro, S.L., Brown, K.W., Thoresen, C., \& Plante, T.G. (2011). The moderation of mindfulness-based stress reduction effects by trait mindfulness: Results from a randomized controlled trial. Journal of Clinical Psychology, 67(3), 267-277. https://doi. org/10.1002/jclp.20761.

Shapiro, S.L., Carlson, L.E., Astin, J.A., \& Freedman, B. (2006). Mechanisms of mindfulness. Journal of Clinical Psychology, 62(3), 373-386. https://doi.org/10.1002/jclp. 20237.

Shapiro, S.L., Schwartz, G.E., \& Santerre, C. (2002). Meditation and positive psychology. In S.J. Lopez \& C.R. Snyder (Eds.), The Oxford handbook of positive psychology (2nd edn., pp. 632-645). Oxford: Oxford University Press.

Spielberger, C.D., Gorsuch, R.L., \& Lushene, R.E. (1970). STAI Manual for the StateTrait Anxiety Inventory. Palo Alto, CA: Consulting Psychologists Press.

Spijkerman, M.P.J., Pots, W.T.M., \& Bohlmeijer, E.T. (2016). Effectiveness of online mindfulness-based interventions in improving mental health: A review and meta- 
analysis of randomised controlled trials. Clinical Psychology Review, 45, 102-114. https://doi.org/10.1016/j.cpr.2016.03.009.

Strauss, C., Cavanagh, K., Oliver, A., \& Pettman, D. (2014). Mindfulness-based interventions for people diagnosed with a current episode of an anxiety or depressive disorder: A meta-analysis of randomised controlled trials. PLOS ONE, 9(4), e96110. https://doi. org/10.1371/journal.pone.0096110.

Wimberley, T.E., Mintz, L.B., \& Suh, H. (2016). Perfectionism and mindfulness: Effectiveness of a bibliotherapy intervention. Mindfulness, 7(2), 433-444. https://doi.org/ 10.1007/s12671-015-0460-1. 